\title{
Honorary issues dedicated to the 60-th anniversary of Professor Ihor Stasyuk
}

On 23 September 1998, Professor Ihor Stasyuk will celebrate his 60th birthday. On this occasion the Editorial Board of "Condensed Matter Physics" as well as his collegues and collaborators wish to honour him with a collection of scientific papers. Many researchers from Ukraine and around the world answered positively to the request of contributing their papers to the celebration issues. To these we express our sincere gratitude. The original papers and reviews widely cover the fields of theoretical physics and condensed matter theory which are of Professor Ihor Stasyuk's scientific interest. Two issues of "Condensed Matter Physics" (1998, vol. 1, No 1(13), 2(14)) contain articles on the theory of systems with strong electron correlations, high-temperature superconductors, selected problems of theoretical physics and condensed matter theory, hydrogen-bonded systems and ferroelectrics, as well as the general issues of the solid state theory. We were not able to include into this collection of papers scientific works (except for two papers) by representatives of a large scientific school of Professor Stasyuk.

Professor Ihor Stasyuk is well-known Ukrainian physicist-theorist, Corresponding Member of the National Academy of Sciences of Ukraine, full member of the Shevchenko Scientific Society, Doctor of Science in Physics and Mathematics.

Ihor Stasyuk was born on the 23th of September 1938, in Berezhany Ternopil' region. He graduated from school in 1954 in Stryj. The same year he entered Lviv State University (Department of Physics) and graduated from it in 1959 with honours.

Ihor Stasyuk started his early research work already during student years and 
continued it during his postgraduate studies (1959-1962) guided by Professor Abba Glauberman. The result of his postgraduate study was his Cand.Sci. (Ph.D.) thesis "The Method of Site Elementary Excitations in the Theory of Nonmetallic Crystals" (1963). In 1962, he received the position of an assistant, then assistant professor of the Department of the Solid State Theory and Department of Theoretical Physics at I. Franko Lviv State University. During 1978-1983 Ihor Stasyuk continued his research work at the Institute of Applied Problems of Mechanics and Mathematics of the Academy of Sciences of Ukraine. Since 1983 Ihor Stasyuk has been working at Lviv Division of the Institute for Theoretical Physics (ITP) of the Academy of Sciences of Ukraine. In 1995 his research activity led to the Doctoral (Habilitation) thesis "Theory of Induced by External Fields Effects in Crystals with Structural Phase Transitions". In 1990, Lviv Division of the ITP was reorganized into the Institute for Condensed Matter Physics (ICMP) of the National Academy of Sciences of Ukraine. Since the foundation of the ICMP Ihor Stasyuk is the Research Deputy Director and Head of the Quantum Statistics Department.

In 1995, Ihor Stasyuk was elected the Corresponding Member of the National Academy of Sciences of Ukraine.

The main scientific achievements of Professor I.Stasyuk concern the solid state theory. He is widely recognized for developing mathematical methods of the multilevel systems theory and his research of Fermi-systems with strong short-range correlations and physical phenomena in crystals with phase transitions. Professor I. Stasyuk made essential contributions to the theory of various effects induced by external fields in crystals, to parametric optics and investigation of anharmonic systems. Today Professor Stasyuk is one of the leading Ukrainian scientists in the field of the theory of ferroelectrics and hydrogen bonded systems. He is the author of more than 370 scientific papers.

Professor I. Stasyuk is a prominent teacher. He always combines his research work with the educational activites. Twelve researchers under his supervision became Candidates of Sciences; two now are Doctors of Sciences. Numerous generations of students of Lviv State University remember his brilliant lectures in Theoretical Physics, as well as more specific courses in quantum statistics, group theory, solid state theory, phase transitions theory, mathematical methods in theoretical physics, etc.

Professor I. Stasyuk is an active organizer of sciece, associate editor of the "Condensed Matter Physics". Ihor Stasyuk has been head and a member of organizing and programme committees of many international and Ukrainian physical conferences.

Editorial Board of the "Condensed Matter Physics", collaborators from the Institute for Condensed Matter Physics and the authors of this honorary collection congratulate Professor Ihor Stasyuk on his 60th birthday and wish him good health and many more years of fruitful scientific work. 


\section{List of main publications of Prof. Dr. Ihor V. Stasyuk}

1. Glauberman A.E., Vladimirov V.V., Stasyuk I.V. New form of polar model for crystal. // Doklady AN SSSR, 1959, vol. 126, No 3, p. 543-545 (in Russian).

2. Glauberman A.E., Vladimirov V.V., Stasyuk I.V. Theory of elementary excitations in atomic crystals. // Fiz. Tverd. Tela, 1960, vol. 2, No 1, p. 133-143 (in Russian).

3. Stasyuk I.V., Glauberman A.E. On the theory of elementary excitations in systems with spin-closed background. // Fiz. Tverd. Tela, 1961, vol. 3, No 7, p. 2089-2096 (in Russian).

4. Stasyuk I.V., Glauberman A.E. On the many electron theory of semiconductors with impurities. // Ukr. Fiz. Zhurn., 1961, vol. 6, No 5, p. 642-654 (in Ukrainian).

5. Stasyuk I.V. Method of site elementary excitations in the theory of nonmetallic crystals. Abstract of thesis for a scientific degree of candidate of physics and mathematics. Lviv, 1963, 7 p.

6. Stasyuk I.V. On method of nodal elementary excitation forspin-unclosed background. In: Questions of solid state physics, Lviv: Ed. Lviv univer., 1964, p. 3-17 (in Ukrainian).

7. Glauberman A.E., Stasyuk I.V. Nodal elementary excitation method in the theory of semiconductors. // Ukr. Fiz. Zhurn., 1964, vol. 9, No 1, p. 3-13 (in Ukrainian).

8. Didukh L.D., Stasyuk I.V. On the theory of exchange interactions in antiferromagnetics with accounting of polar excitations. // Izv. Acad. Nauk SSSR, Ser. Fiz., 1966, vol. 30, No 6, p. 915-920 (in Russian).

9. Didukh L.D., Stasyuk I.V. On exchange interactions in antiferromagnetics. // Fiz. Metallov i Metallovedenie, 1968, vol. 26, No 3, p. 435-442 (in Russian).

10. Didukh L.D., Stasyuk I.V. On the theory of ferromagnetism in polar model. // Ukr. Fiz. Zhurn., 1968, vol. 13, No 6, p. 899-904 (in Ukrainian).

11. Didukh L.D., Stasyuk I.V. On the ferromagnetism theory with allowance for s-d transition. // Ukr. Fiz. Zhurn., 1968, vol. 13, No 11, p. 1774-1780 (in Russian).

12. Didukh L.D., Stasyuk I.V. Spin-wave approach of ferromagnetic with accounting of polar excitations. // Ukr. Fiz. Zhurn., 1968, vol. 13, No 11, p. 1924-1926 (in Russian).

13. Stasyuk I.V., Levitsky R.R. On elementary excitations in ferroelectrics with hydrogen bond. // Ukr. Fiz. Zhurn., 1969, vol. 14, No 7, p. 1097-1105 (in Ukrainian).

14. Stasyuk I.V., Levitsky R.R. Coupled vibrations of a proton-ion system in ferroelectrics with hydrogen bonds of $\mathrm{KH}_{2} \mathrm{PO}_{4}$ type. // Ukr. Fiz. Zhurn., 1970, vol. 15, No 3, p. 460-469 (in Russian).

15. Stasyuk I.V. Equations for spin correlators in the Ising model. // Fiz. Metallov i Metallovedenie., 1971, vol. 31, No 4, p. 699-704 (in Russian).

16. Stasyuk I.V. Proton-phonon interaction in ferroelectrics with hydrogen bonds (strong coupling approximation). // Teor. Mat. Fiz., 1971, vol. 9, No 3, p. 431-439 (in Russian). 
17. Stasyuk I.V., Levitsky R.R. Dynamical theory of $\mathrm{NH}_{4} \mathrm{H}_{2} \mathrm{PO}_{4}$-type antiferroelectrics with hydrogen bonds. // Izv. Acad. Nauk SSSR, Ser. Fiz., 1971, vol. 35, No 9, p. 1775-1778 (in Russian).

18. Didukh L.D., Stasyuk I.V. On ground state energy and ferromagnetism condition in narrow s-band. // Fiz. Metallov i Metallovedenie, 1972, vol. 33, No 2, p. 429-431 (in Russian).

19. Stasyuk I.V., Kaminskaya N.M. Theory of spontaneous polarization and deformation of $\mathrm{KH}_{2} \mathrm{PO}_{4}$ type ferroelectrics. I. Role of long-range forces in phase transition. // Ukr. Fiz. Zhurn., 1974, vol. 19, No 2, p. 237-243 (in Ukrainian).

20. Stasyuk I.V., Kaminskaya N.M. Theory of spontaneous polarization and deformation of $\mathrm{KH}_{2} \mathrm{PO}_{4}$ type ferroelectrics. II. Consideration of peculiarities interproton interaction. // Ukr. Fiz. Zhurn., 1974, vol. 19, No 2, p. 244-252 (in Ukrainian).

21. Stasyuk I.V., Yakibchuk P.M. Theory of phase transition in the Slater model with account of polar states of protons. // Ukr. Fiz. Zhurn., 1974, vol. 19, No 4, p. 653-658 (in Ukrainian).

22. Stasyuk I.V., Slobodyan P.M. Diagram technique for the Hubbard operators. // Teor. Mat. Fiz., 1974, vol. 19, No 3, p. 423-428 (in Russian).

23. Levitsky R.R., Korinevsky M.A., Stasyuk I.V. A theory of proton ordering in ferroelectrics and antiferroelectrics of orthophosphate type. // Ukr. Fiz. Zhurn., 1974, vol. 19, No 8, p. 1289-1297 (in Russian).

24. Levitsky R.R., Stasyuk I.V. Approximation of self-consistent field in the de Gennes model. // Ukr. Fiz. Zhurn., 1974, vol. 19, No 8, p. 1331-1338 (in Russian).

25. Popel A.M., Stasyuk I.V., Vlokh O.G. Microscopic theory of electrooptical effect in $\mathrm{KH}_{2(1-x)} \mathrm{D}_{2 x} \mathrm{PO}_{4}$ (DKDP) crystals. // Fiz. Tverd. Tela., 1974, vol. 16, p. 3526-3528 (in Russian).

26. Popel A.M., Stasyuk I.V. Theory of electrooptic effect in deuterated crystals $\mathrm{KH}_{2} \mathrm{PO}_{4}$ (KDP). // Ukr. Fiz. Zhurn., 1975, vol. 20, No 4, p. 598-607 (in Ukrainian).

27. Stasyuk I.V., Kaminskaya N.M. Microscopic theory for elastic properties of $\mathrm{KH}_{2} \mathrm{PO}_{4}$ type crystals. // Izv. Acad. Nauk SSSR, Ser. Fiz., 1975, vol. 39, No 4, p. 690-692 (in Russian).

28. Lukiyanets B.A., Tovstyuk K.D., Stasyuk I.V. The magnetic behaviour of adatoms on the crystal surface. // Phys. Stat. Sol. (b), 1975, vol. 68, p. K87-K90.

29. Levitsky R.R., Stasyuk I.V., Korynevsky N.A. Dynamics of ferroactive crystals of orthophosphate type. // Ferroelectrics, 1978, vol. 21, p. 481-483.

30. Levitsky R.R., Korynevsky N.A., Stasyuk I.V. Distribution function and thermodynamical properties of $\mathrm{KD}_{2} \mathrm{PO}_{4}$ and $\mathrm{ND}_{4} \mathrm{D}_{2} \mathrm{PO}_{4}$ type crystals. // Phys. Stat. Sol. (b), 1978, vol. 88, No 1, p. 51-63.

31. Didukh L.D., Pryadko L.F., Stasyuk I.V. Correlational effects in narrow-band materials. Lviv: Ed. Vyshcha shkola, 1978, 120 p. (in Russian).

32. Kozitsky Y.V. Levitsky R.R., Stasyuk I.V. Polariton states in the order-disorder type ferroelectrics. // Teor. Mat. Fiz., 1979, vol. 39, No 1, p. 106-117 (in Russian). 
33. Stasyuk I.V., Levitsky R.R., Korinevsky N.A. Collective vibrations of protons in compounds of $\mathrm{KH}_{2} \mathrm{PO}_{4}$ - type. // Phys. Stat. Sol. (b), 1979, vol. 91, No 2, p. 541550 .

34. Grigorchuk R.O., Stasyuk I.V. Electron-deformation interaction and lattice contraction in crystals described by a Hubbard model. // Ukr. Fiz. Zhurn., 1980, vol. 25, No 3, p. 404-410 (in Russian).

35. Stasyuk I.V., Mokhnyak S.M. On band spectrum in deformated narrow-band semiconductor. // Fiz. elektronika., 1980, issue 20, Lviv: Ed. Vyshcha shkola, 1980, p. 33-39 (in Russian).

36. Stasyuk I.V., Saban A.Ya. On thermodynamic theory of Jahn-Teller phase transitions in crystals with tetragonal symmetry. / Preprint ITP-81-99R, Kyiv, 1981, 16 p. (in Russian)

37. Stasyuk I.V., Saban A.Ya. Elementary excitations in Jahn-Teller crystals of rareearth vanadates. I. Mean field approximation. / Preprint ITP-81-145R, Kyiv, 1981, $28 \mathrm{p}$.

38. Stasyuk I.V., Saban A.Ya. Elementary excitations in Jahn-Teller crystals of rareearth vanadates type. II. Isothermal and "isolated" susceptibilities. / Preprint ITP81-146R, Kyiv, 1981, 20 p.

39. Stasyuk I.V., Kotsur S.S. On microscopic theory of electrooptic activity of ferroelectric crystals with hydrogen bonds. // Ukr. Fiz. Zhurn., 1982, vol. 27, No 3, p. 393-400 (in Russian).

40. Stasyuk I.V., Grigorchuk R.A. The theory of the strain effects in the crystals described by the s(d)-f model. // Phys. Stat. Sol. (b), 1982, vol. 112, No 1, p. 327-338.

41. Stasyuk I.V., Biletsky I.N. On the influence of bulk and uniaxial pressures on phase transitions in $\mathrm{KH}_{2} \mathrm{PO}_{4}$ type crystals. // Izv. Acad. Nauk SSSR, Ser. Fiz., 1983, vol. 47, No 4, p. 705-709. (in Russian).

42. Vlokh O.G., Stasyuk I.V., Korobyi Y.S., Kotsur S.S., Lazko L.A. On dispersion and temperature dependence of electrogyration in the lead germanate and molibdanate crystals. // Izv. Acad. Nauk SSSR, Ser. Fiz., 1983, vol. 47, No 4, p. 665-668 (in Russian).

43. Stasyuk I.V., Kotsur S.S. The microscopic theory of the gyration and electrogyration in dielectric crystals. // Phys. Stat. Sol. (b), 1983, vol. 117, No 2, p. 557-568.

44. Stasyuk I.V., Tupychak V.P., Yatsyshyn V.P. Elastic properties of thulium arsenate on the non-axial stress. // Ukr. Fiz. Zhurn., 1984, vol. 29, No 9, p. 1333-1337 (in Russian).

45. Ivankiv A.L., Stasyuk I.V., Grigorchuk R.A. To the fluctuation effects during phase transitions with valence variation. // Ukr. Fiz. Zhurn., 1984, vol. 29, No 12, p. 18371842 (in Russian).

46. Grigas J., Kalesinskas V., Stasyuk I.V. Soft microwave mode in SbSJ-type crystals. // Ferroelectrics, 1984, 55, No 1, p. 31-34.

47. Stasyuk I.V., Yukhnovskii P.I. The hybridization influence on state $\mathrm{H}^{-}$of hydrogen in metal. / Preprint ITP-84-100R, Kyiv, 1984, 37p. (in Russian). 
48. Stasyuk I.V. Theory of induced by external fields effects in crystals with structural phase transitions. Thesis abstract for a scientific degree of doctor of physics and mathematics, Kyiv, 1985, 38p. (in Russian).

49. Stasyuk I.V., Kotsur S.S. On the theory of electrogyration in dielectric crystals. Sheelite-type crystals. // Phys. Stat. Sol. (b), 1985, vol. 130, No 1, p. 103-113.

50. Stasyuk I.V., Levitsky R.R., Saban A.Ya. Theory of induced by external fields effects and relaxation phenomena in crystals with structural and ferroelectric phase transitions. In: Problems of modern statistical physics, Kyiv: Nauk. Dumka, 1985, p. 274-285 (in Russian).

51. Stasyuk I.V., Ivankiv Ya.L. Raman light scattering in crystals with ordering elements of structure. / Preprint ITP-87-57R, Kyiv, 1987, 25p. (in Russian).

52. Stasyuk I.V., Ivankiv A.L. Microscopic theory of quadratic electrooptic effect and electrogyration in ferroelectric dielectric crystals. // Ferroelectrics Letters, 1988, vol. 8, No 1, p. 65-69.

53. Ivankiv A.L., Stasyuk I.V. Microscopic theory of the quadratic electrooptic effect in dielectric crystals. // Ukr. Fiz. Zhurn., 1988, vol. 33, No 4, p. 513-521 (in Russian).

54. Stasyuk I.V., Kotsur S.S., Stetsiv R.Ya. Natural and induced optical activity of ferroelectric crystals possessing ordering structure units. // Ferroelectrics Letters, 1988, vol. 8, No 1, p. 71-74.

55. Plakida N.M., Stasyuk I.V. On the theory of superconductivity in the Hubbard model. // Mod. Phys. Lett.B, 1988, vol. 2, No 8, p. 969-977.

56. Stasyuk I.V., Shvaika A.M., Mokhnyak S.M. Rotational ability of centrosymmetric layered media. // Ferroelectrics Letters, 1988, vol. 10, No 1, p. 113-116.

57. Kotsur S.S., Stasyuk I.V. The quantum theory of the optical activity of ionic dielectric crystals. // Phys. Stat. Sol. (b), 1989, vol. 155, No 2, p. 697-707.

58. Shvaika A.M., Stasyuk I.V., Mokhnyak S.M. On the microscopic theory of optical properties of crystals with incommensurate phases. // Phys. Stat. Sol. (b), 1989, vol. 156, No 1, p. 377-382.

59. Plakida N.M., Yushankhai V.Y., Stasyuk I.V. On the role of kinematic and exchange interactions in superconducting electron pairing of electrons in the Hubbard model. // Physica C, 1989, vol. 160, No 1, p. 80-88.

60. Plakida N.M., Yushankhai V.Y., Stasyuk I.V. On d-wave pairing in one band Hubbard model. // Physica C, 1989, vol. 162-164, p. 787-788.

61. Stasyuk I.V., Kotsur S.S., Tupychak V.P. On the theory of the Faraday effect in dielectric ionic crystals and crystals with structural phase transition of Jahn-Teller type. // Phys. Stat. Sol. (b), 1990, vol. 160, No 2, p. 683-696.

62. Stasyuk I.V., Ivankiv A.L. Reduced set model for explanation of the molecular complexes with chains of hydrogen bonds. // Ukr. Fiz. Zhurn., 1991, vol. 36, No 6, p. 817-823 (in Ukrainian).

63. Stasyuk I.V., Ivankiv A.L., Grigorchuk R.O. Thermodynamic functions of proton subsystem for molecular complexes with hydrogen-bonded chains. // Ukr. Fiz. Zhurn., 1991, vol. 36, No 7, p. 1000-1006 (in Ukrainian). 
64. Stasyuk I.V., Stamenkovic S., Ivankiv A.L. Energy spectrum of the proton subsystem of molecular complexes with hydrogen-bonded chains. // Ukr. Fiz. Zhurn., 1991, vol. 36, No 9, p. 1305-1313 (in Ukrainian).

65. Stasyuk I.V., Kotsur S.S. Tupychak V.P. On the theory of the Faraday effect in Jahn-Teller type crystals. // Izv. Acad. Nauk SSSR, Ser. Fiz., 1991, vol. 55, No 3, p. 457-463 (in Russian).

66. Stasyuk I.V., Stetsiv R.Ya. Electronic states and optical effects in $\mathrm{KH}_{2} \mathrm{PO}_{4}$ type crystals with hydrogen bonds. // Izv. Acad. Nauk SSSR, Ser. Fiz., 1991, vol. 55, No 3, p. 522-525 (in Russian).

67. Stasyuk I.V., Peleshchak R.M. Occupation of electron states and metal lattice deformation in the vicinity of a boundary separating regions with different mechanical stresses. // Ukr. Fiz. Zhurn., 1991, vol. 36, No 11, p. 1744-1749 (in Ukrainian).

68. Stasyuk I.V., Ivankiv A.L. Thermodynamics of the molecular complexes with chains of hydrogen bonds. // Mod. Phys. Lett. B., 1992, vol. 6, No 2, p. 85-91.

69. Stasyuk I.V., Kotsur S.S., Ivankiv A.L., Dublenych Y.I. Low-frequency dynamics of $\mathrm{CuO}$ chains of finite length in $\mathrm{YBa}_{2} \mathrm{Cu}_{3} \mathrm{O}_{7-x}$ high $\mathrm{T}_{c}$ superconductors. // Sverkhprovodimost:FChT, 1992, vol. 5, No 4, p. 584-588 (in Russian).

70. Stasyuk I.V., Ivankiv A.L. Thermodynamic properties of molecular and crystallite systems with chains of hydrogen bonds. // Kristallografia (Soviet. Phys.- Cryst.), 1992, vol. 37, No 3, p. 551-558 (in Russian).

71. Stasyuk I.V., Shvaika A.M. Dielectric properties and electron spectrum of the Muller model in the HTSC theory. // Acta Physica Polonica A, 1993, vol. 84, No 2, p. 293313.

72. Stasyuk I.V., Shvaika A.M., Schachinger E. On the electron spectrum of the Hubbard model including interactions with local anharmonic vibrations. // Physica C, 1993, vol. 213, No 1, p. 57-70.

73. Stasyuk I.V., Stetsiv R.Ya. Electron spectrum and optical constants of ferroelectrics with hydrogen bonds. // Ferroelectrics, 1993, vol. 144, p. 195-206.

74. Stasyuk I.V., Shvaika A.M., Schachinger E. The electron spectrum of the Hubbard model with coupling to pseudospin degrees of freedom. // Physica B, 1994, vol. 194196. p. $1965-1966$.

75. Stasyuk I.V., Shvaika A.M. Electron spectrum and dielectric susceptibility of the Hubbard model with local lattice anharmonicity. // Acta Physica Polonica A, 1994, vol. 85 , No 2, p. 363-366.

76. Stasyuk I.V., Shvaika A.M. Dielectric instability and local anharmonic model in the theory of high- $T_{c}$ superconductivity. // Physica C, 1994, vol. 235, p. 2173-2174.

77. Otko A.J., Stasyuk I.V. Internal field and crystallooptical anomalies connected with collinear domains in $\mathrm{LiNbO}_{3}$. // Ferroelectrics, 1995, vol. 172, p. 207-215.

78. Stasyuk I.V., Shvaika A.M., Danyliv O.D. Dielectric instability and charge ordering in the local anharmonic model of high- $T_{c}$ superconductors. // Molecular Physics Reports, 1995, vol. 9, p. 61-75. 
79. Stasyuk I.V., Sizonenko Yu.V. Effective local anharmonic potentials in solids. A model approach. // Condensed Matter Physics, 1995, No 5, p. 161-191.

80. Stasyuk I.V., Shvaika A.M. Dielectric, charge and phase-separation instabilities in pseudospin-electron model of high- $T_{c}$ superconductors. // Czech. J. Phys., 1996, vol. 46, Suppl. 2, p. 961-962.

81. Danyliv O.D, Stasyuk I.V. The analysis of ferroelectric type instabilities in the two-sublattice model of high temperature superconducting systems. // Condensed Matter Physics, 1996, No 7, p. 163-178.

82. Stasyuk I.V., Stetsiv R.Ya., Holubets' T.V. Investigation of influence of external hydrostatic pressure on electron energy spectra of ion groups and optical properties of KDP-type crystals. // Ukr. Fiz. Zhurn., 1996, vol. 41, No 10, p. 910-915. (in Ukrainian).

83. Stasyuk I.V., Ivankiv O.L., Pavlenko N.I. Orientational-tuneling model of onedimensional molecular systems with hydrogen bonds. // J. of Physical Studies, 1997, vol. 1, No 3, p. 418-430.

84. Stasyuk I.V., Pavlenko N.I., Hilczer B. Proton ordering model of superionic phase transition in $\left(\mathrm{NH}_{4}\right)_{3} \mathrm{H}\left(\mathrm{SeO}_{4}\right)_{2}$ crystal. // Phase Transitions, 1997, vol. 62, p. 135153.

85. Stasyuk I.V., Pavlenko N.I., Połomska M. Ferroelectric domain structure of $\left(\mathrm{NH}_{4}\right)_{3} \mathrm{H}\left(\mathrm{SeO}_{4}\right)_{2}$ crystal. // Phase Transitions, 1997, vol. 62, p. 167-179.

86. Stasyuk I.V., Shvaika A.M. Dielectric instability and vibronic-type spectrum of local anharmonic model of high- $T_{c}$ superconductors. // Ferroelectrics, 1997, vol. 192, p. 110.

87. Stasyuk I.V., Trachenko K.O. Investigation of locally anharmonic models of structural phase transitions. Seminumerical approach. // Condensed Matter Physics, 1997, No 9, p. 89-106.

88. Stasyuk I.V., Pavlenko N.I., Hilczer B. Microscopic model of sequence of superionicferroelastic phase transitions in $\left(\mathrm{NH}_{4}\right)_{3} \mathrm{H}\left(\mathrm{SeO}_{4}\right)_{2}$ crystal. // J. Korean Phys. Soc., 1998, vol. 32, p. S24-S27. 